\title{
Background and Rationale
}

\author{
Ana Penman-Aguilar, PhD \\ Karen Bouye, $\mathrm{PhD}$ \\ Leandris Liburd, $\mathrm{PhD}$ \\ Office of Minority Health and Health Equity, Office of the Director, CDC
}

Contributing author: Ana Penman-Aguilar, Office of Minority Health and Health Equity, Office of the Director, CDC. Telephone: 770-488-8194; E-mail: bpv4@cdc.gov.

In 2011, CDC published the first CDC Health Disparities and Inequalities Report (CHDIR) (1). This report examined health disparities in the United States associated with various characteristics, including race/ethnicity, sex, income, education, disability status, and geography. Health disparities were defined as "differences in health outcomes and their determinants between segments of the population, as defined by social, demographic, environmental, and geographic attributes" (1). Among other recommendations, the 2011 CHDIR emphasized the need to address health disparities with a dual intervention strategy focused on populations at greatest need and on improving the health of the U.S. population by making interventions available to everyone. The 2013 CHDIR updated the 2011 CHDIR and included additional reports on social and environmental determinants of health; the supplement emphasized the importance of multisectoral collaboration, highlighting the need for a comprehensive, community-driven approach to reducing health disparities in the United States (2). A follow-up report described five interventions that were shown to be effective or demonstrated promise for reducing health disparities (3). These publications have focused attention on the need to address health disparities in the United States (4), as well as on programs and interventions that address them. This supplement describes additional interventions that address particular disparities observed by race and ethnicity, socioeconomic status, geographic location, disability, and/ or sexual orientation across a range of conditions, including asthma, infection with HIV and hepatitis A, use of colorectal cancer screening, youth violence, food security, and healthrelated quality of life.

One of the four overarching goals of Healthy People 2020, the initiative that establishes the nation's health objectives, is achieving health equity, eliminating disparities, and improving the health of all U.S. population groups (5). Achieving the aim of eliminating health disparities depends on the availability of data for understanding the distribution of health outcomes and social and other determinants of health across population groups, and for determining whether progress in eliminating disparity is being made; these data are necessary to inform intervention efforts. Another goal of Healthy People 2020 is to create social and physical environments that promote good health for all persons (5). Both this goal and that of achieving health equity, eliminating disparities, and improving the health of all population groups relate to the social determinants of health (i.e., the conditions in the environments in which persons are born, live, learn, work, play, worship, and age that affect a wide range of health, functioning, and quality-of-life outcomes and risks) (G). Achieving the goals of Healthy People 2020 requires addressing the social determinants of health and reducing health disparities and health inequities (i.e., health disparities that are systematic, avoidable, and unfair) $(7,8)$.

Several challenges to advancing health equity exist. One such challenge is that health disparities and inequities typically are not specified as outcomes of interest in intervention research studies, which makes it difficult to understand whether equity has been advanced. Another challenge is that when disparities decrease or the health or risks of affected populations improve, determining which factors and strategies contributed to the improvement can be difficult.

This supplement includes CDC-sponsored interventions selected by CDC's Office of Minority Health and Health Equity (OMHHE). Seven of the eight reports describe interventions that have demonstrated effectiveness or showed promise for decreasing health disparities and had sufficient data collected to enable evaluation.

The first report describes important community-driven and participatory approaches and reflects efforts of tribal communities to connect efforts to reclaim their lands, foods, language, and culture to improving the health of their people (9). Although sufficient evaluation data for demonstrating effectiveness or promise cannot be presented at this time, the report was included because it describes culturally relevant approaches to reducing health disparities. The second report describes Boston Children's Hospital's Community Asthma Initiative, which demonstrated that community health workers can be effective agents of change in communities (10). The third report describes the use of evidence-based interventions to improve levels of screening for colorectal cancer in two states, in Alaska (among Alaska Natives) and in Washington (among racial and ethnic minority and low-income populations). In this report, the use of established evidence-based interventions helped in the attribution of observed outcomes or effects 
(thus addressing one of the challenges mentioned above) (11). The fourth report documents the reduction of disparities in hepatitis A virus (HAV) infection following incremental changes in hepatitis A vaccination recommendations to increase coverage for children and persons at high risk for HAV infection; description of health disparities as program outcomes is an important strength of this report (12). The fifth and sixth reports outline how the Personalized Cognitive Counseling (PCC) HIV prevention intervention and Project ECHO and the HoMBReS and HoMBReS por un Cambio interventions have been demonstrated to reduce HIV- and STD-related risk behaviors among Hispanic or Latino men and men who have sex with men, respectively $(13,14)$. Similar to the Boston Children's Hospital's Community Asthma Initiative, which involved community health workers, the HoMBReS and HoMBReS por un Cambio report points to the important role of lay health advisors in addressing health disparities. Involving lay health advisors and community health workers can help ensure the cultural and linguistic appropriateness of interventions, which is critical for their success (15). The seventh report demonstrates how the social determinants of health can be addressed effectively by community-level strategies; the report describes three community-level interventions that were linked to reductions in youth violence, presumably by influencing social determinants (16). The eighth report describes an intervention that addresses disparities in health-related quality of life (17) that were shown in the 2013 CHDIR to affect persons who experience disabilities (18).

The reports in this $M M W R$ supplement address important challenges to the health of the U.S. population. It is only through implementing evidence-based interventions and supporting ongoing efforts that Healthy People 2020 goals can be achieved.

\section{Acknowledgment}

Lynne S. Wilcox, MD, was science editor for this supplement.

\section{References}

1. CDC. CDC health disparities and inequalities report-United States, 2011. MMWR Suppl 2011;60(Suppl; January 24, 2011).

2. CDC. CDC health disparities and inequalities report-United States, 2013. MMWR Suppl 2013;62(No. Suppl 3).

3. CDC. Strategies for reducing health disparities-selected CDCsponsored interventions, United States, 2014. MMWR Suppl 2014;63(No. Suppl 1).

4. Frieden TR. Foreword. In: CDC health disparities and inequalities report-United States, 2013. MMWR Suppl 2013;62(No. Suppl 3).
5. US Department of Health and Human Services. Healthy people 2020. Washington, DC: US Department of Health and Human Services; 2011. http://www.healthypeople.gov.

6. US Department of Health and Human Services, Office of Disease Prevention and Health Promotion. Healthy people 2020: social determinants. Washington, DC: US Department of Health and Human Services; 2015. http://www.healthypeople.gov/2020/leading-healthindicators/2020-lhi-topics/Social-Determinants.

7. Braveman P, Gruskin S. Defining equity in health. J Epidemiol Community Health 2003;57:254-8. http://dx.doi.org/10.1136/ jech.57.4.254.

8. Braveman P. Health disparities and health equity: concepts and measurement. Annu Rev Public Health 2006;27:167-94. http://dx.doi. org/10.1146/annurev.publhealth.27.021405.102103.

9. Satterfield D, DeBruyn L, Santos M, Alonso L, Frank M. Health promotion and diabetes prevention in American Indian and Alaska Native communities-Traditional Foods Project, 2008-2014. In: Strategies to reduce health disparities: selected CDC-sponsored interventions-United States, 2016. MMWR Suppl 2016;65(No. Suppl 1).

10. Woods ER, Bhaumik U, Sommer SJ, et al. Community asthma initiative to improve health outcomes and reduce disparities among children with asthma. In: Strategies to reduce health disparities: selected CDCsponsored interventions-United States, 2016. MMWR Suppl 2016;65(No. Suppl 1).

11. Joseph DA, Redwood D, DeGroff A, Butler EL. Use of evidence-based interventions to address disparities in colorectal cancer screening. In: Strategies to reduce health disparities: selected CDC-sponsored interventions-United States, 2016. MMWR Suppl 2016;65(No. Suppl 1).

12. Murphy TV, Denniston M, Hill HA, McDonald M. Progress toward eliminating hepatitis A disease in the United States. In: Strategies to reduce health disparities: selected CDC-sponsored interventionsUnited States, 2016. MMWR Suppl 2016;65(No. Suppl 1).

13. Herbst JH, Raiford JL, Carry MG, Wilkes AL, Ellington RD, Whittier DK. Adaptation and national dissemination of a brief, evidence-based, HIV prevention intervention for high-risk men who have sex with men. In: Strategies to reduce health disparities: selected CDC-sponsored interventions_-United States, 2016. MMWR Suppl 2016;65(No. Suppl 1).

14. Rhodes SD, Leichliter JS, Sun CJ, Bloom FR. The HoMBReS and HoMBReS Por un Cambio interventions to reduce HIV disparities among immigrant Hispanic/Latino men. In: Strategies to reduce health disparities: selected CDC-sponsored interventions_-United States, 2016. MMWR Suppl 2016;65(No. Suppl 1).

15. US Department of Health and Human Services, Office of Minority Health. CLAS and the national CLAS standards. Washington, DC: US Department of Health and Human Services, Office of Minority Health; 2015. https://www.thinkculturalhealth.hhs.gov/Content/clas.asp.

16. Massetti GN, Davod-Ferdon C. Preventing violence among high-risk youth and communities with economic, policy, and structural strategies. In: Strategies to reduce health disparities: selected CDC-sponsored interventions_-United States, 2016. MMWR Suppl 2016;65(No. Suppl 1).

17. Ravesloot C, Seekins T, Traci M, et al. Living Well with a Disability, a self-management program. In: Strategies to reduce health disparities: selected CDC-sponsored interventions-United States, 2016. MMWR Suppl 2016;65(No. Suppl 1).

18. Zack MM. Health-related quality of life-United States, 2006 and 2010. MMWR Suppl 2013;62(No. Suppl 3). 